University of Nebraska - Lincoln

DigitalCommons@University of Nebraska - Lincoln

2010

\title{
Self-Assembly and Properties of Nonmetalated Tetraphenyl- Porphyrin on Metal Substrates
}

\author{
Geoffrey Rojas \\ University of Nebraska-Lincoln, geoff.rojas@gmail.com \\ Xumin Chen \\ University of Nebraska-Lincoln \\ Cameron Bravo \\ University of Nebraska-Lincoln \\ Ji-Hyun Kim \\ Sookmyung Women's University, Seoul, Korea \\ Jae-Sung Kim \\ Sookmyung Women's University, Seoul, Korea \\ See next page for additional authors
}

Follow this and additional works at: https://digitalcommons.unl.edu/physicsenders

Part of the Physics Commons

Rojas, Geoffrey; Chen, Xumin; Bravo, Cameron; Kim, Ji-Hyun; Kim, Jae-Sung; Xiao, Jie; Dowben, Peter A.; Gao, Yi; Zeng, Xiao Cheng; Choe, Wonyoung; and Enders, Axel, "Self-Assembly and Properties of Nonmetalated Tetraphenyl-Porphyrin on Metal Substrates" (2010). Axel Enders Publications. 35. https://digitalcommons.unl.edu/physicsenders/35

This Article is brought to you for free and open access by the Research Papers in Physics and Astronomy at DigitalCommons@University of Nebraska - Lincoln. It has been accepted for inclusion in Axel Enders Publications by an authorized administrator of DigitalCommons@University of Nebraska - Lincoln. 


\section{Authors}

Geoffrey Rojas, Xumin Chen, Cameron Bravo, Ji-Hyun Kim, Jae-Sung Kim, Jie Xiao, Peter A. Dowben, Yi Gao, Xiao Cheng Zeng, Wonyoung Choe, and Axel Enders 


\title{
Self-Assembly and Properties of Nonmetalated Tetraphenyl-Porphyrin on Metal Substrates
}

\author{
Geoffrey Rojas, ${ }^{1}$, Xumin Chen, ${ }^{1}$, Cameron Bravo, ${ }^{1}$, Ji-Hyun Kim, ${ }^{2}$ Jae-Sung Kim, ${ }^{1,2}$ Jie Xiao, ${ }^{1}$ \\ Peter A. Dowben, ${ }^{1,3}$ Yi Gao, ${ }^{4}$ Xiao Cheng Zeng, ${ }^{4}$ Wonyoung Choe, ${ }^{4}$ and Axel Enders ${ }^{1,3}$ \\ 1. Department of Physics, University of Nebraska-Lincoln, Lincoln, Nebraska 68588 \\ 2. Department of Physics, Sookmyung Women's University, Seoul, 140-741, South Korea \\ 3. Nebraska Center for Materials and Nanoscience \\ 4. Department of Chemistry, University of Nebraska-Lincoln, Lincoln, Nebraska 68588 \\ Corresponding author — A. Enders, email a.enders@me.com
}

\begin{abstract}
The structure-electronic structure relationship of nonmetalated meso-tetraphenyl porphyrin (2H-TPP) on the (111) surfaces of $\mathrm{Ag}, \mathrm{Cu}$, and $\mathrm{Au}$ was studied with a combination of scanning tunneling microscopy, photoelectron spectroscopy, and density functional theory. We observe that the molecules form a 2D network on $\mathrm{Ag}(111)$, driven by attractive intermolecular interactions, while the surface migration barriers are comparatively small and the charge transfer to the adsorbed molecules is minimal. This is in contrast to a significant charge transfer observed in $2 \mathrm{H}-\mathrm{TPP} / \mathrm{Cu}(111)$, resulting in repulsive forces between the molecules that prevent molecular adlayer network formation. It is shown that the limiting factor in formation of self-organized networks is the nature of the frontier orbital overlap and the adsorbate-interface electron transfer. Further, the electronic structure, most notably the HOMO-LUMO splitting, are found to be dependent on the substrate as well. The comparison of the results in this article with published work on similar porphyrins suggests that the molecule-substrate interaction strength is determined by the molecule's metalation, and not so much by the ligands.
\end{abstract}

\section{Introduction}

The self-assembly of porphyrins on well-defined surfaces is attracting considerable interest because it promises to create surface patterns with nanometer dimension that exhibit specific electronic, sensoric, optic, or catalytic functionality ${ }^{1-3}$ or even interesting magnetic properties. ${ }^{4,5}$ The ability of porphyrin to show self-organization and to accommodate metal atoms in their macrocycle is exploited, for instance, to form metal-organic frameworks or adsorbed layers for catalysis. ${ }^{6-9}$ The selfassembly is mainly driven by noncovalent metal-organic coordination interactions, which is well-known and important in solution-based $3 \mathrm{D}$ supramolecular chemistry. ${ }^{10-15}$

Porphyrin molecules have been adsorbed onto surfaces to form supramolecular networks from solution, ${ }^{16-19}$ electrochemically ${ }^{20,21}$ or by thermal evaporation under vacuum conditions. ${ }^{22-28}$ While there is a rich literature on the electronic structure of these adsorbates, the surface adlayer structures have also been characterized with scanning force microscopy, scanning tunneling microscopy, or X-ray absorption near-edge structure analysis. ${ }^{29}$ The rationale of such experiments on $2 \mathrm{D}$ structures has been to study the long-range interactions that determine the self-assembly processes. It has been demonstrated that the bottom-up fabrication of highly organized porphyrin layers, as well as of porphyrin-based multicomponent molecular entities, depends on the interplay of molecule-molecule and substrate-molecule interactions. Molecule-substrate interactions will set limits to the mobility of the adsorbed molecules and may alter the electronic structure of the absorbed molecules, or the electronic states at the surfaces may become locally perturbed by the adsorbate. ${ }^{60}$ A consequence is that the established concepts of solution-based coordination chemistry cannot be ap- plied without appropriate modification. The substrate thus becomes an additional parameter to control the adsorption energy of the molecules and, hence, their diffusivity at surfaces. An intriguing demonstration of this effect is the self-assembly of porphyrins, which are decoupled from their metal substrate by insulating $\mathrm{NaCl}$ layers of varying thickness. ${ }^{23}$ The interaction was shown to be dependent on the $\mathrm{NaCl}$ layers, and the thicker the $\mathrm{NaCl}$ the weaker the interaction and the more delayed the onset of network formation. The occupation of the center ring of the porphyrin may affect the molecular adsorption at surfaces. As an example, free-base or $\mathrm{Cu}$-incorporated porphyrin molecules show different arrangements along step edges on $\mathrm{Cu}(100)$ surfaces. While $2 \mathrm{H}$-TBPP bridges over the step edges, $\mathrm{Cu}$-TBPP sits on either side of step edges. ${ }^{27}$ In contrast, no difference in the network architecture was found for differently metalated TPP on $\operatorname{Ag}(111) .57$ Such a subtle dependence of adsorption site on metal incorporation, if fully understood, may become useful to control the self-assembly or the properties of the molecules on surfaces.

The goal of the present work is to investigate the competition between noncovalent intermolecular interactions and molecule-substrate interactions for $2 \mathrm{H}-\mathrm{TPP}$ on $\mathrm{Ag}(111), \mathrm{Cu}(111)$, and $\mathrm{Au}(111)$ and to establish the structure-properties relationship and its dependence on interactions with the supporting substrate.

\section{Experimental Section}

$\mathrm{Ag}(111)$ and $\mathrm{Cu}(111)$ single crystals of purity $>99.999 \%$ were prepared by repeated cycles of Ar ion sputtering and annealing at temperatures of 850 and $800 \mathrm{~K}$, respectively, for multiple cycles in ultrahigh vacuum (UHV) conditions $\left(<1 \times 10^{-10} \mathrm{mBar}\right)$. The substrate's cleanliness was checked by STM at $80 \mathrm{~K}$ before deposition of organic material, as well as by photoemission. 
The 5,10,15,20-tetraphenyl-21H,23H-porphine (2H-TPP) was purchased from Frontier Scientific (purity $>97 \%$ ) and used without further modification. Molecules were deposited by evaporation using a home-built Knudsen Cell evaporator. Molecules were evaporated at a rate of approximately $0.05 \mathrm{ML} / \mathrm{min}$ at crucible temperatures of approximately $500 \mathrm{~K}$. Coverages were initially limited to approximately $\Theta \simeq$ o.o1 ML, where a monolayer $(\mathrm{ML})$ is defined as coverages of approximately $5.1 \times 10^{13}$ molecules $/ \mathrm{cm}^{-2}$, and gradually increased by successive evaporation cycles as needed. For a comparison of molecular adsorption, the 2H-TPP adlayers were studied after evaporation onto $\mathrm{Ag}(111)$ and $\mathrm{Cu}(111)$ under identical growth conditions.

Samples were immediately transferred in situ to an adjoining chamber for scanning tunneling microscopy (STM) measurements. Image data were obtained under constant current mode using an Omicron Nanotechnology low temperature STM (LT STM) with a tungsten tip at $80 \mathrm{~K}$ and pressures of low $10^{-11} \mathrm{mBar}$. Combined photoemission (UPS) and inverse photoemission spectra (IPES) were taken in a separate UHV system using the same single crystal substrates and evaporators. In all spectroscopy measurements, the binding energies are referenced with respect to the Fermi level of the substrates in close contact with the sample surface. The IPES were obtained by using variable energy electrons incident along the sample surface normal while measuring the emitted photons at a fixed energy $(9.7 \mathrm{eV})$ using a Geiger-Müller detector. The instrumental line width is $400 \mathrm{meV}$, as described elsewhere. ${ }^{37}$ The angle integrated photoemission (UPS) studies were carried out using a helium lamp at $h v=\mathbf{2 1 . 2}$ $\mathrm{eV}$ (He I) and a Phi hemispherical electron analyzer with an angular acceptance of $\pm 10^{\circ}$ or more, as also described elsewhere. ${ }^{37}$

Calculations were performed using density functional theory (DFT) utilizing the generalized-gradient approximation (GGADFT) HCTH functional. $4^{\mathrm{o}-42}$ The double numerical polarized basis sets (DNP) with the semicore pseudo potentials were applied for all atoms, including $\mathrm{Ag}, \mathrm{C}, \mathrm{N}$, and $\mathrm{H}$ atoms. $43,44 \mathrm{~A}$ 2-layer $10 \times$ 1o silver slab was used to simulate the $\operatorname{Ag}(111)$ surface substrate. In addition, a layer with $10 \times 4 \mathrm{Ag}(111)$ surface was placed on top of the slab to simulate the step-edge effects. In order to reduce the computational cost, the substrate was frozen while the $2 \mathrm{H}$ TPP was fully relaxed. All calculations were performed by using the $\mathrm{DMol}^{3}$ software package. ${ }^{43,44}$

\section{Growth Studies with STM}

2H-TPP on $\mathbf{A g}(\mathbf{1 1 1})$. The $2 \mathrm{H}$-TPP adlayers were studied after evaporation onto $\mathrm{Ag}(111)$ and $\mathrm{Cu}(111)$ under identical growth conditions. First, submonolayer aliquots of the $2 \mathrm{H}$-TPP molecules were evaporated onto a $\operatorname{Ag}(111)$ substrate at $300 \mathrm{~K}$. The substrate was subsequently cooled to liquid nitrogen temperatures $(T=77 \mathrm{~K})$ for STM studies. For very low $2 \mathrm{H}$-TPP coverage, $(\Theta<$ o.o1 ML), molecules are exclusively observed at the substrate step edges, while nothing is seen on the terraces. Higher resolution STM images, as in Figure 1 (a), show that those $2 \mathrm{H}$ TPP molecules straddle the step edges, with the phenyl ligands oriented with an angle of approximately $\phi=21^{\circ}$ relative to the boundary of the step-edge. All observed step-edge phase molecules sit across the Ag(n1) step-edges in apparently identical geometries. These molecules are not seen to engage in any lateral motion even over the period of several hours. Increasing the $2 \mathrm{H}$ TPP coverage resulted in an increase of the step-edge occupancy, until every step edge was fully occupied.

Molecules nucleated into clusters on the terraces only after complete occupation of the step-edges, resulting in ordered two-dimensional networks as those seen in Figure 1b,c. Clearly

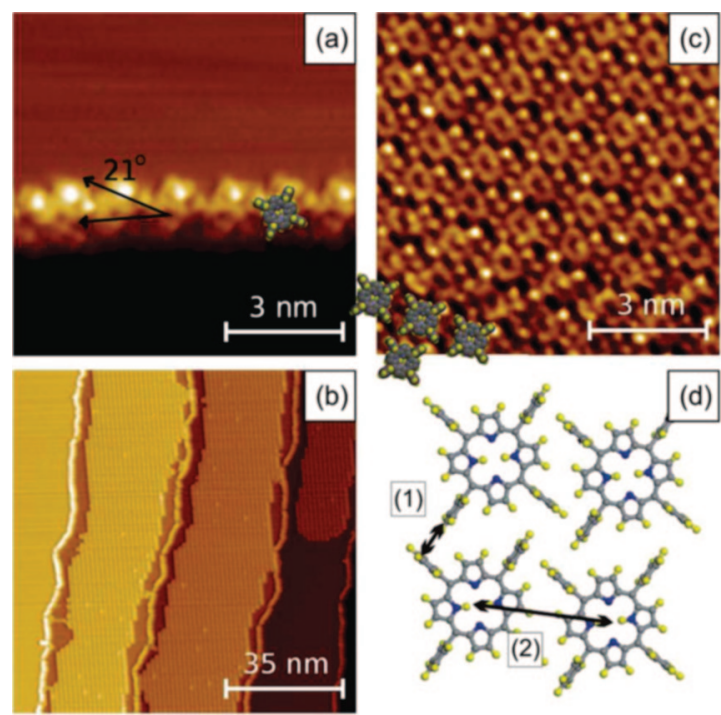

Figure 1. STM images of $2 \mathrm{H}$-TPP molecules adsorbed on $\mathrm{Ag}(111)$. (a) $\Theta<$ o.o1 ML, all observed molecules located saddling step edges. (b) $\Theta \simeq 0.5$ ML, (c) Close-up of molecules on terraces from (b) showing the relative orientation of the molecules. (d) Schematic illustration of measured intermolecular distances for (1) CH- $\pi$ interaction at 3.9(3) Å and (2) unit cell dimension of 13.(9) $\AA$. All images taken at $I=0.8 \mathrm{nA}, V_{\mathrm{Gap}}=-0.90 \mathrm{nA}$.

visible in this figure is the coexistence of the step-edge phase $\mathrm{e}^{27}$ with extended $2 \mathrm{D}$ networks of $2 \mathrm{H}$-TPP at a coverage of $(\Theta \simeq 0.5$ $\mathrm{ML}$ ), while (c) provides a detailed view of the molecular arrangement in the network. The molecules are found to order in tetragonal unit cells of length $a=13.8 \AA$, and to be rotated by $16^{\circ}$ relative to the axis of the network (Figure 1d). Similar $2 \mathrm{D}$ arrangement can be found in bulk phases of TPP molecules incorporated with various metals such as $\mathrm{Ti}, \mathrm{V}, \mathrm{Cr}, \mathrm{Fe}, \mathrm{Co}, \mathrm{Cu}, \mathrm{Zn}, \mathrm{Ru}, \mathrm{Mg}$, Sn, and Ge. ${ }^{45^{-}}$ 47 The tetragonal unit cell parameter $a$ obtained from X-ray single crystal diffraction of these phases ranges from 13.3 to $13.8 \AA, 45-47$ comparable to the same parameter from our surface pattern. Interestingly, the metal free $2 \mathrm{H}$-TPP molecules in bulk phase do not form this observed tetragonal $2 \mathrm{D}$ pattern. ${ }^{45-47}$ The $\mathrm{CH}-\pi$ spacing of $3.9 \AA$, found in Figure $1 d$, is also comparable to the tetragonal phase of metalated TPP bulk phases.

The orientation of the adsorbed molecules shows a clear influence of the underlying substrate crystallography, as we found three characteristic domains with main directions separated by roughly $60^{\circ}$, following $\operatorname{Ag}(111)$ substrate symmetry.

We conclude from the STM studies that $2 \mathrm{H}-\mathrm{TPP}$ is highly mobile on $\mathrm{Ag}(111)$ at $300 \mathrm{~K}$ except at step-edges, with a mean diffusion length significantly larger than the mean terrace width of our substrate. The substrate step-edges, however, provide efficient pinning sites for the porphyrin molecules. The $2 \mathrm{D}$ network formation on the terrace is mainly driven by attractive molecule-molecule interaction while the interaction between the molecules and the substrate, specifically the migration barriers, are comparatively weak.

The same arrangement of molecules has been reported for 2H-TPP on the same substrate, as well as on Au(111). 56,57,59 The geometry of the molecules and the limitations imposed by multiple interactions with neighboring molecules, including potential $\mathrm{CH}-\pi$ interactions between phenyl ligands and $\mathrm{C}-\mathrm{H}$ pairs on neighboring macrocycles, determines the arrangements of molecules at surfaces, has, for example, been suggested in Reference 57. Calculations were performed to further examine these interactions and will be discussed later. 


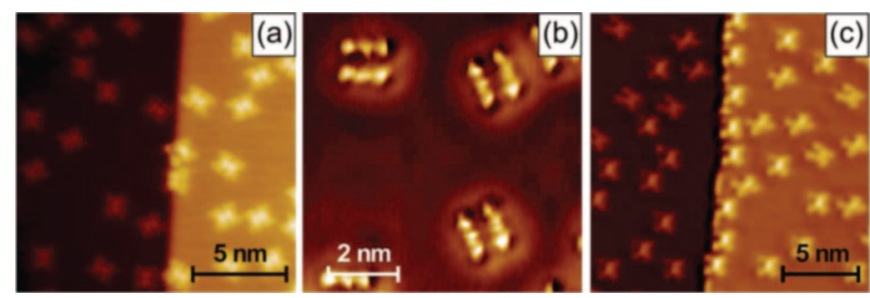

Figure 2. STM images of $2 \mathrm{H}-\mathrm{TPP}$ chemisorbed on a cleaned $\mathrm{Cu}(111)$ substrate at $T=300 \mathrm{~K}$ and taken at $V=-0.8 \mathrm{~V}$ with a tunneling current of $I=$ $0.90 \mathrm{nA}(\mathrm{a})$, a close-up image of the molecule taken at $V=+0.4 \mathrm{~V}$ and $I=$ $0.8 \mathrm{nA}(\mathrm{b})$, and after annealing to $T=350 \mathrm{~K}$ taken with bias voltage of $V$ $=-1.0 \mathrm{~V}$ and $I=1.4 \mathrm{nA}(\mathrm{c})$.

2H-TPP on Cu(111). 2H-TPP molecules were evaporated onto $\mathrm{Cu}(111)$ under conditions described in the previous section. STM images of submonolayer coverages of $2 \mathrm{H}$-TPP on $\mathrm{Cu}(111)$, taken at $77 \mathrm{~K}$, are summarized in Figure 2. The molecules were not observed to form $2 \mathrm{D}$ networks on $\mathrm{Cu}(111)$, unlike $\mathrm{Ag}(111)$. Rather, they tend to be randomly distributed across the terraces and remain isolated from neighboring molecules. No tendency toward step decoration was observed. The molecules appear to be oriented along the principal crystallographic directions of the underlying surface structure, as concluded from the generally observed angle of $120^{\circ}$ between the major axes of any two closely adjacent molecules.

Observation of the molecules over significant lengths of time showed no lateral motion of the molecules over the substrate, contrary to what was seen for terrace-adsorbed molecules on $\mathrm{Ag}(111)$. Furthermore, the molecules on $\mathrm{Cu}(111)$ appear topologically distinct from the same molecular species adsorbed on the $\operatorname{Ag}(111)$. Under identical scanning conditions, the molecules appear with a raised center and 2 -fold symmetry on $\mathrm{Cu}$ as seen for metalated species, ${ }^{48}$ while on Ag they appear as ring-like structures with dark centers and clearly resolved arms. However, the appearance of the molecules is dependent on the bias voltage during the STM experiment, as a comparison of Figure 2, panels $\mathrm{a}$ and $\mathrm{b}$, shows. At sufficiently low bias voltage, a ring becomes visible in the substrate in the vicinity of chemisorbed molecules (Figure 2b). This ring is ascribed to the formation of a surface dipole at the molecule site by drawing electrons from the substrate, leaving the molecules negatively charged. This surface induced dipole, along with greatly increased migration barrier for $\mathrm{Cu}(111)^{49}$ seems to be related to the absence of self-assembled ordered structures of $2 \mathrm{H}$-TPP on $\mathrm{Cu}(111)$.

In an attempt to overcome the diffusion barriers, the molecule-substrate system was annealed to higher temperatures (Figure 2c). Following moderate annealing to $350 \mathrm{~K}$ for $2 \mathrm{~min}$, the molecules were seen to partially decorate the step edge, shown in Figure 2c. The step-edge occupancy was observed to become complete only after all further annealing to $450 \mathrm{~K}$. The molecules occupying the step-edges in the $2 \mathrm{H}-\mathrm{TPP} / \mathrm{Cu}(111)$ remained seated at the top of the step-edge on the terrace and aligned with the axis of the molecule parallel with the step-edge boundary. No bridging of the step-edges, similar to $2 \mathrm{H}-\mathrm{TPP} /$ $\operatorname{Ag}(111)$, was observed. Despite this observed motion on the terraces, the $2 \mathrm{H}-\mathrm{TPP}$ molecules did not exhibit any $2 \mathrm{D}$ lateral organization on the $\mathrm{Cu}(111)$ terraces for all annealing temperatures studied up to $450 \mathrm{~K}$.

Photoelectron Spectroscopy. Combined photoemission and inverse photoemission spectra have been taken for submonolayer, monolayer, and multilayer coverages of $2 \mathrm{H}-\mathrm{TPP}$ on $\mathrm{Ag}, \mathrm{Au}$, and $\mathrm{Cu}$ substrates. The goal was to correlate the occupied and unoccupied electronic states of the molecules in contact with the

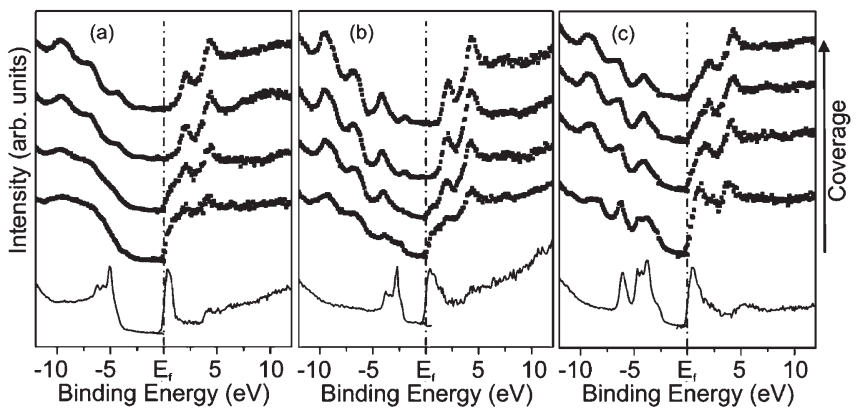

Figure 3. Coverage dependent photoemission and inverse photoemission spectra (symbols) of metal-free porphyrin ( $2 \mathrm{H}-\mathrm{TPP})$ adsorbed at $300 \mathrm{~K}$ in coverages (from bottom to top) of $\simeq 0.5,1,3$, and $8 \mathrm{ML}$ on (a) $\mathrm{Ag}(111)$, (b) $\mathrm{Cu}(111)$, and (c) $\mathrm{Au}(111)$. Shown at the bottom of each panel is the spectra of the pristine substrates as reference.

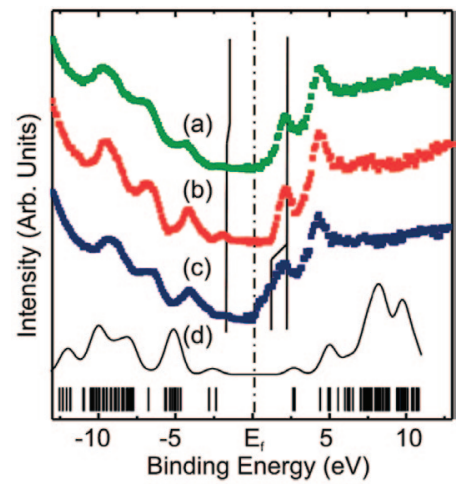

Figure 4. Comparison of photoemission and inverse photoemission spectra of multilayers of $2 \mathrm{H}$-TPP (nominally 5 ML) on $\mathrm{Ag}(111)$ (a), Cu(111) (b), and $\mathrm{Au}(111)$ (c). The barcodes at the bottom are the calculated molecular orbital eigenvalues, and spectra $(d)$ is the calculated single molecule density of states. The LUMO splitting from $\mathrm{Au}$ to $\mathrm{Ag}$ and $\mathrm{Cu}$ as well as the HOMO are indicated by vertical lines between spectra.

metal surfaces with the observed structures. UPS and IEPS spectra obtained as function of molecule coverage, together with spectra from the pristine substrates, are summarized in Figure 3.

Features resulting from the occupied and unoccupied molecular orbitals were clearly observed at all coverages for the $\mathrm{Cu}(111)$ and $\mathrm{Au}(111)$ systems (Figure $3 \mathrm{~b}, \mathrm{c}$ ) in the combined photoemission and inverse photoemission. In contrast, peaks due to the molecular orbitals are difficult to distinguish in the occupied states at low 2H-TPP coverages on $\mathrm{Ag}(\mathrm{ml1})$ (Figure 3a). All the photoemission spectra show a rapid decrease in those peaks of the underlying substrates with increasing molecule coverage. The generally good agreement of the low coverage combined photoemission and inverse photoemission spectra of $2 \mathrm{H}$-TPP on $\mathrm{Cu}(111)$ and $\mathrm{Au}(111)$ is remarkable, and consistent with the observed planar adsorption geometry. The absence of clear states at low coverages for $2 \mathrm{H}$-TPP on $\mathrm{Ag}(111)$ is attributed to the coexistence of different adsorption geometries as observed with STM, and will be discussed later.

At greater thicknesses, features from the molecules become resolved also on $\mathrm{Ag}(111)$ (Figure 4). Similarities of the electronic structure in $2 \mathrm{H}$-TPP films are apparent for all three substrates studied. Those features are also in good agreement with the calculated spectra, also shown at the bottom of Figure 4. The calculated spectrum is based on simplistic single molecule semiempirical method $\mathrm{NDO}-\mathrm{PM}_{3}$ model calculations based on Hartree-Fock formalism, neglecting differential diatomic overlap and assuming a parametric model number of 3, all performed using SPARTAN 8.0.5 Geometry optimization of the molecule 
Table 1. Orbitals and Energies of a Single 2H-TPP Molecule ${ }^{\mathrm{a}}$

\begin{tabular}{lrccc}
\hline & calcuated & $\mathrm{Cu}$ & $\mathrm{Ag}$ & $\mathrm{Au}$ \\
\hline HOMO - 1 $(\mathrm{eV})$ & -2.73 & -4.10 & -4.30 & -4.10 \\
HOMO $(\mathrm{eV})$ & -2.37 & -1.90 & -1.90 & -1.90 \\
LUMO $(\mathrm{eV})$ & 2.63 & 2.10 & 2.10 & 1.00 \\
LUMO + 1 (eV) & 2.82 & & & 2.10 \\
gap $(\mathrm{eV})$ & 5.00 & 4.00 & 4.00 & 2.90 \\
radius & & 1.45 & 1.65 & 1.74 \\
\hline
\end{tabular}

a. Calculated values are from $\mathrm{PM}_{3}$ calculations in SPARTAN; $\mathrm{Cu}, \mathrm{Ag}$, and Au are from $8 \mathrm{ML}$ samples on the respective substrates.

was performed by obtaining the lowest restricted Hartree-Fock energy states. The calculated density of states (DOS) shown was obtained by applying equal Gaussian envelopes of $1 \mathrm{eV}$ full width half-maximum to each molecular orbital and then summing to account for the solid state broadening in photoemission. This model density of states calculation was rigidly shifted in energy, largely to account for the influence of work functions on the orbital energies, and no corrections were made for molecular interactions and final state effects.

Photoemission and inverse photoemission are final state spectroscopies, and the HOMO-LUMO gap has been estimated from the vertical energies, with corrections included for the measured instrumental line widths. The combined photoemission and inverse photoemission provides an estimate of the HOMO-LUMO gap of 4.00 to $2.90 \mathrm{eV}$, depending on substrate, as summarized in Table 1 . This means the HOMO-LUMO gap of a thin film is strongly dependent on the underlying substrate, showing a difference as large as $25 \%$. We further note that the HOMO-LUMO gap predicted by the ground state theory is larger than that measured, which is unusual. The observed HOMO-LUMO gaps for the $2 \mathrm{H}-\mathrm{TPP} / \mathrm{Ag}(111)$ and $2 \mathrm{H}-\mathrm{TPP} / \mathrm{Cu}(111)$ systems differ from those reported for bulk samples ${ }^{51}$ in that they are significantly larger. A splitting of the LUMO state is seen for the $2 \mathrm{H}-\mathrm{TPP} / \mathrm{Au}(111)$ system, and weakly also for the $2 \mathrm{H}-\mathrm{TPP} /$ $\mathrm{Ag}(111)$ system. Such splitting indicate either strong intermolecular or substrate interactions, and is in fact consistent with the close packed $2 \mathrm{H}-\mathrm{TPP}$ on $\mathrm{Ag}(111)$, as discussed later. No such splitting is seen for the $\mathrm{Cu}(111)$.

Density Functional Theory. Calculations of molecules and dimers of $2 \mathrm{H}$-TPP on $\mathrm{Ag}(111)$ were performed in order to gauge the effect of molecule-molecule and molecule-substrate interactions, and their influence on the aggregation of molecules at the surface. It is known that traditional DFT methods often cannot reproduce the weak interactions qualitatively and quantitatively due to the lack of dispersion. ${ }^{52}$ In order to test the applicability of the HCTH functional in this system, we examined the binding energy of a benzene dimer. Binding energies for the Tshaped and sandwich benzene dimer of 0.04 and $0.02 \mathrm{eV}$ were obtained, respectively. Although these values are much smaller than the results based on high level $\operatorname{CCSD}(\mathrm{T})$ calculations, 53 it gives a correct qualitative description of van der Waals interactions, which means the HCTH functional could be used to evaluate the $\sigma-\pi$ and $\pi-\pi$ interactions.

With our calculations we optimized a $2 \mathrm{H}-\mathrm{TPP}$ monomer on a $\mathrm{Ag}$ terrace and on a step edge, as well as free $2 \mathrm{H}$-TPP dimers. On the $\operatorname{Ag}(111)$ surface, the molecules were found to exhibit little distortion of the overall shape, with the porphyrin molecules centered above a $\operatorname{Ag}(111)$ lattice site. The dihedral angle of the phenyl arms of $2 \mathrm{H}$-TPP on a $\mathrm{Ag}(111)$ terrace was found to be $70.5^{\circ}$, which is reasonably close to previously reported $60^{\circ}$ for an isolated $2 \mathrm{H}$-TPP molecule. ${ }^{5,60,61}$ On the step edge, the phenyl arms

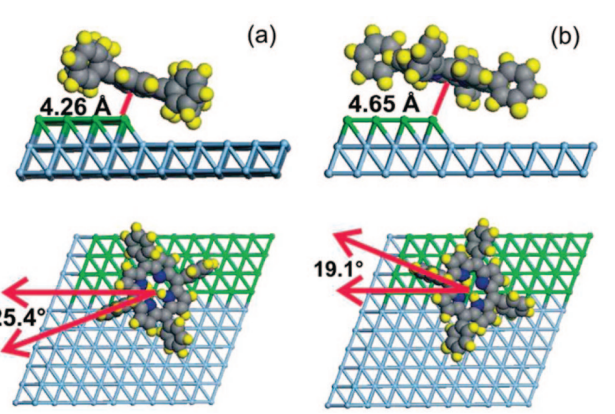

Figure 5. GGA-HCTH calculated adsorption geometry of $2 \mathrm{H}-\mathrm{TPP}$ at a step-edge initially oriented with ligand directions at (a) $45^{\circ}$ and (b) parallel to the direction of the step-edge.

are rotated between $69^{\circ}$ and $74^{\circ}$ depending on adsorption geometry. Considering the very slight energy change $(0.03 \mathrm{eV})$ with the dihedral rotation from $60^{\circ}$ to $90^{\circ}, 64$ the small dihedral angle change of $2 \mathrm{H}$-TPP reflects the interaction between Ag surface and the $2 \mathrm{H}$-TPP molecule.

The molecule-molecule total binding energy for a free porphyrin dimer was found to be $0.15 \mathrm{eV}$, due to a combination of van der Waals, electrostatic, $\mathrm{CH}-\pi$, and $\pi-\pi$ interactions. In contrast, the resulting binding energy of a $2 \mathrm{H}$-TPP monomer to the $\mathrm{Ag}(111)$ terrace was found to be $0.44 \mathrm{eV}$. The diffusion barrier for a single molecule on the $\mathrm{Ag}(111)$ surface was found to be $0.032 \mathrm{eV}$, on the same order as that seen for other organic adsorbates on $\mathrm{Ag}(111)$ surfaces. ${ }^{54}$ For comparison, the kinetic energy at 300 and 77 K would be 0.026 and $0.007 \mathrm{eV}$ respectively. Such a small surface diffusion barrier would allow for the molecules to move along the surface, making single lattice jumps before interacting with another at room temperature, as well as at liquid nitrogen temperatures at a reduced rate. The resulting distance of a $\mathrm{CH}-\pi$ interaction in $2 \mathrm{H}-$ TPP dimers on a $\operatorname{Ag}(111)$ terrace was found to be $3.03 \AA$, which is only slightly shorter than what was observed with the STM.

Further DFT calculations show the binding between $2 \mathrm{H}-\mathrm{TPP}$ and the $\mathrm{Ag}(111)$ terrace comes from modest electron transfer between the Ag surface and the adsorbed $2 \mathrm{H}$-TPP molecule, where the molecule takes up $0.191 e$ according to a Hirshfeld analysis. Meanwhile, the electrostatic potential surface (ESP) indicates that the negative electrostatic potential of the inner porphyrin ring of $2 \mathrm{H}$-TPP has an interaction with the positive electrostatic potential of the $\operatorname{Ag}(111)$ surface, which could explain the nature of the $2 \mathrm{H}$-TPP adsorption on $\mathrm{Ag}(111)$ surface.

Calculations were undertaken for individual molecules bridging the step-edge in multiple orientations. First, a single $2 \mathrm{H}-\mathrm{TPP}$ molecule was tested with the molecule initially bridging a $\mathrm{Ag}(\mathrm{m11})$ step-edge with all phenyl ligands $45^{\circ}$ to the boundary of the stepedge. It was found by structural optimization that in this orientation the molecule bound to the substrate at an angle of $28^{\circ}$ between the molecule plane and the substrate surface, and at a distance of $4.26 \AA$ (Figure 5). The phenyl arms and the step edge enclose an in-plane angle of $25.4^{\circ}$, and the net binding energy was calculated as $0.39 \mathrm{eV}$. When calculations were run with the molecule initially oriented with two phenyl arms parallel to the boundary of the step-edge and two normal, this molecule rotated upon optimization to an orientation similar to that observed by the STM (exp: in-plane angle of $21^{\circ}$, calculated: in-plane angle of $19^{\circ}$; Figures ia and $5 \mathrm{~b}$, respectively). The resulting molecule-substrate distance was found to be $4.65 \AA$ and the binding energy was found to be $0.55 \mathrm{eV}$ and the Hirshfeld analysis found the Ag gives 0.193 $e$ to $2 \mathrm{H}$-TPP molecules. In both examples, the binding energy for the molecules at the step edge is larger than on flat terraces, explaining the found preferential step decoration. 

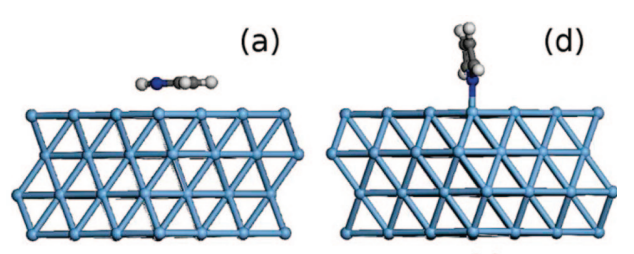

(b)
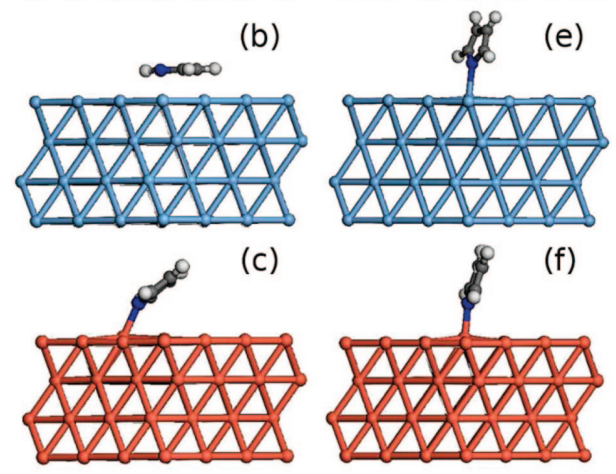

Figure 6. Calculated adsorption geometry of pyrroline molecules at $\mathrm{Cu}(111)$ and $\mathrm{Ag}(111)$ surfaces. The orientations of the molecules (a) initially parallel to the substrate and after convergence for (b) pyrroline parallel to $\mathrm{Ag}(111)$ and (c) pyrroline parallel to $\mathrm{Cu}(111)$. The orientations of the molecules $(\mathrm{d})$ initially normal to the substrate and after convergence for (e) pyrroline normal to $\mathrm{Ag}(111)$ and (f) pyrroline normal to $\mathrm{Cu}(111)$.

Computation of the interactions of the $2 \mathrm{H}-\mathrm{TPP}$ molecule or dimer on the $\mathrm{Cu}(111)$ substrate were infeasible for us. However, given the highly preferential binding of the $2 \mathrm{H}$-TPP molecules over step edges on $\mathrm{Ag}(111)$, the limiting interaction of the $2 \mathrm{H}$ $\mathrm{TPP} / \mathrm{Cu}(111)$ system were thought to be due to the nitrogens of the porphyrin macrocycle interacting strongly with the underlying $\mathrm{Cu}(111)$ atoms as per similar interactions claimed for $2 \mathrm{HT}$ $\mathrm{PyP} / \mathrm{Cu}(111) .55$ In making a computational comparison between the $\mathrm{Ag}(111)$ and $\mathrm{Cu}(111)$ systems, calculations were thus performed for lone pyrroline molecules as representing components of the porphyrin macrocycle which have the strongest potential interaction with the substrate. Two types of calculations were performed, one with the pyrroline initially parallel to the substrate, representing $2 \mathrm{H}$-TPP in the terrace phase (Figure 6a) and one with the pyrroline initially normal to the substrate, representing $2 \mathrm{H}$-TPP in the step-edge phase (Figure $6 \mathrm{~d}$ ).

It was found that for those pyrroline molecules which began initially parallel to the underlying substrates, the simulations of the pyrroline on $\mathrm{Ag}(111)$ did not converge (Figure 6b), despite being attempted in several different initial orientations. For the pyrroline/ $\mathrm{Cu}(111)$ system the molecule bound to the underlying substrate with an energy of $1.49 \mathrm{eV}$ (Figure 6c). For those pyrroline molecules initially normal, both the pyrroline/Ag(111) (Figure 6e) and the pyrroline/Cu(111) (Figure 6f) converged to a strong chemical bond with the substrate. However, the energy of the pyrroline $/ \mathrm{Cu}(111)$ bond $(1.5 \mathrm{O} \mathrm{eV})$ was more than twice that of the pyrroline $/ \mathrm{Ag}(111)$ bond $(0.73 \mathrm{eV})$. In both cases for the $\mathrm{Cu}(111)$ substrate, the molecule-substrate system converged to a strong bond due to overlap of the $\pi$-orbitals of the pyrroline with the $\mathrm{d}$ orbitals of the underlying $\mathrm{Cu}$ as per the LDOS.

Taken from these results it is concluded that for the $2 \mathrm{H}$ $\mathrm{TPP} / \mathrm{Cu}(111)$ system, there was no energetic preference for the molecules binding to the step edge over binding to the underlying terrace. The overlap in the orbitals calculated would be strong enough to create a significant bond of the porphyrin macrocycle with the underlying substrate regardless of initial orientation. In contrast, a clear preference for step decoration was seen both experimentally and from the $2 \mathrm{H}-\mathrm{TPP} / \mathrm{Ag}(111)$ and pyrroline/Ag(111) calculations.

\section{Discussion}

Our observations can be summarized as follows: (i) $2 \mathrm{H}-\mathrm{TPP}$ are highly mobile on $\mathrm{Ag}(111)$ and prefer to occupy substrate step edges in a bridging position, with an angle between phenyl arms and the step edge of approximately $20^{\circ}$. Upon achieving $100 \%$ step-edge occupancy, extended $2 \mathrm{D}$ networks are formed on the terraces. (ii) $2 \mathrm{H}$-TPP on $\mathrm{Cu}(111)$ does not show any tendency of surface diffusion or self-assembly. The mobility was increased at elevated temperatures, but still no network formation or step edge bridging was observed. The formation of a surface dipole at the molecule sites is observed with STM. (iii) Photoelectron spectroscopy of the occupied and unoccupied states show distinct and easily discernible peaks generally matching published UPS data and theoretical expectations. ${ }^{63,82-84}$ For low and moderate $2 \mathrm{H}$-TPP coverages on Ag, distinctive molecular orbital features of the occupied states are absent and peak splitting of the LUMO is observed for $2 \mathrm{H}-\mathrm{TPP} / \mathrm{Au}(111)$ by inverse photoemission. (iv) DFT calculations show that the binding energy for $2 \mathrm{H}$-TPP on $\mathrm{Ag}$ in various positions and geometries is largest for a bridging position at step edges, with rotated "X" geometry, whereas the binding energy of the nitrile components of the macrocycle is larger by more than a factor of 2 on $\mathrm{Cu}(111)$ and independent of the adsorption site.

The observed ordering of the molecules on the terraces of $\mathrm{Ag}(111)$ has also been reported for the same molecules on $\operatorname{Ag}(111)^{58,59}$ and for metalated TPP molecules on $\mathrm{Cu}(111)^{57}$ and is consistent with what has previously been reported for similar systems of porphyrin molecules on noble metal substrates. ${ }^{21,56,66-70}$ However, the very strong preferential and ordered bonding the molecules show toward the surface stepedges has not been reported thus far. Also, the observed absence of self-assembly for $2 \mathrm{H}$-TPP on $\mathrm{Cu}(111)$ is in striking difference to the networks reported for Co-TPP or $\mathrm{Cu}$-TPP on $\mathrm{Cu}(111) .57$

To explain the preferred step edge adsorption, we have presented energy calculations by DFT-GGA for various absorption geometries on step-edges, by varying the angle between the phenyl arms and the step edge as well as the inclination of the molecule against the step-edge. As a result, the experimentally observed orientation of the $2 \mathrm{H}$-TPP was found to have the highest binding energy, about $125 \%$ higher than what was calculated for the molecules occupying terrace sites. The preferential step edge decoration is not related to the $2 \mathrm{H}$-TPP macrocycle metalation, as comparative measurements with Ag-TPP on the same $\mathrm{Ag}(111)$ substrate showed, which is also in agreement with arguments made in Reference 57. We thus suggest that the observed geometry is largely due to a simple energetic favorability of geometric orientations. The achieved geometrical closeness of the nitrogen atoms in the porphyrin macrocycle to the $\mathrm{Ag}$ atoms of the step-edge cannot be achieved on terraces where the rotated phenyl arms determine the macrocycle-substrate distance, explaining the higher binding energy at the step edges.

Our calculation showed further that the energy of the T-type interaction between neighboring phenyl ligands is 1 order of magnitude smaller than the total binding energy of a $2 \mathrm{H}$-TPP dimer. It is thus concluded that the self-assembly of $2 \mathrm{H}$-TPP into the $2 \mathrm{D}$ networks observed on $\mathrm{Ag}(111)$ is the result of the interplay between several factors. It is driven by the attractive interaction between the molecules, but only possible if the $2 \mathrm{H}$-TPP interacts weakly with the substrate underneath so that diffusion barriers are sufficiently low. The attractive $\mathrm{CH}-\pi$ bonds, regarded as the 


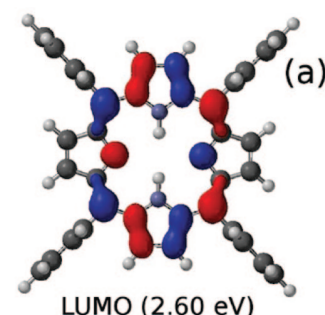

LUMO (2.60 eV)

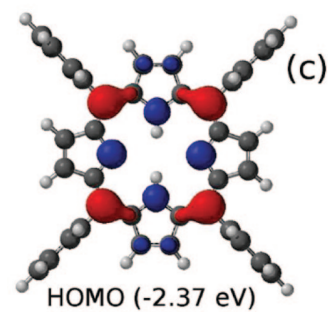

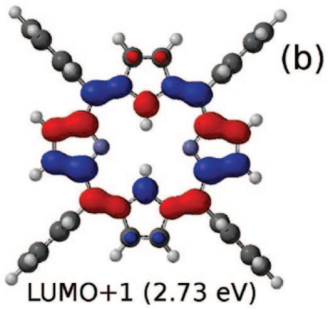

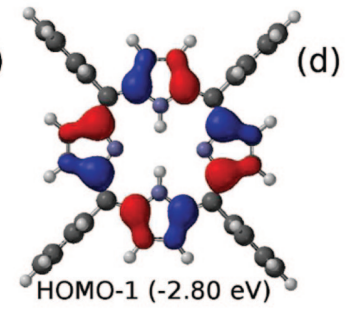

Figure 7. Orbitals corresponding to semiempirical NDO-PM3 model calculations. (a) LUMO, (b) LUMO + 1, (c) HOMO, and (d) HOMO - 1.

driving force for network formation in Reference 57, are alone insufficient to overcome the diffusion barriers on $\operatorname{Ag}(111)$, but do determine the alignment of neighboring molecules with respect to each other, or in other words, the network's geometry.

In contrast to what has been found for $2 \mathrm{H}$-TPP on $\mathrm{Ag}(111)$ and for metalated TPP on $\mathrm{Cu}(111), 57$ no self-assembly of $2 \mathrm{H}$-TPP is observed on $\mathrm{Cu}(111)$. Networks are also not formed at increased temperatures, when the molecule's diffusion rates are already substantial. It is thus concluded that on $\mathrm{Cu}(111)$ the interaction between $2 \mathrm{H}$-TPP is repulsive, which can only be the result of the interaction with the $\mathrm{Cu}$ substrate. The pickup of charges by the molecules from the substrate can result in the formation of a electric dipole and hence electrostatic repulsion between molecules, thereby inhibiting network formation. Such a charge pickup by the $2 \mathrm{H}$-TPP is observed with STM on $\mathrm{Cu}(111)$, where the modification of the substrate around isolated $2 \mathrm{H}-\mathrm{TPP}$ molecules is clearly visible as a ring, which is in analogy to the observed sombrero-like shape of charged metal atoms on insulating films ${ }^{75}$ or TCNE molecules on $\operatorname{Ag}(100) .{ }^{81}$ This modified electronic structure surrounding the molecule corresponds well with those predicted and observed for simple two body molecules on $\mathrm{Cu}(\mathrm{oo1}) .7^{8}$ This electron exchange then leads to longrange, electrostatic repulsive molecule-molecule interactions as seen also for other species.79,81

A comparison of our findings on $2 \mathrm{H}-\mathrm{TPP}$ on $\mathrm{Cu}(111)$ with published STM data on metalated TPP or TPyP on the same substrate $^{48,57,62}$ seems further to suggest that not the ligands but rather the macrocycle metalation is controlling the self-assembly: nonmetalated molecules with different ligands (2H-TPP, $\mathrm{TPy})$ remain isolated on the $\mathrm{Cu}(111)$, while only metallated TPP are observed to form networks. This conclusion is backed by related studies of molecule-substrate interactions that conclude that the metal ion in the porphyrin macrocycle plays the central role in the electronic interaction between the complexes and the metal surface, which was even found to result in additional electronic states. ${ }^{6} 3$

Qualitatively, the $\mathrm{Cu}$ system possesses $\mathrm{a} \mathrm{d}_{z}^{2}$ orbital extending into the vacuum while the outermost orbitals for the Ag and the $\mathrm{Au}$ system are more dominated by the frontier $s$ orbitals. The calculated molecular orbitals from our semiempirical calculations of the free molecule, and matching those found with GGA-DFT calculations, are shown in Figure 7. It is apparent that the HOMO orbital possesses $a_{1 u}$ symmetry and the LUMO and

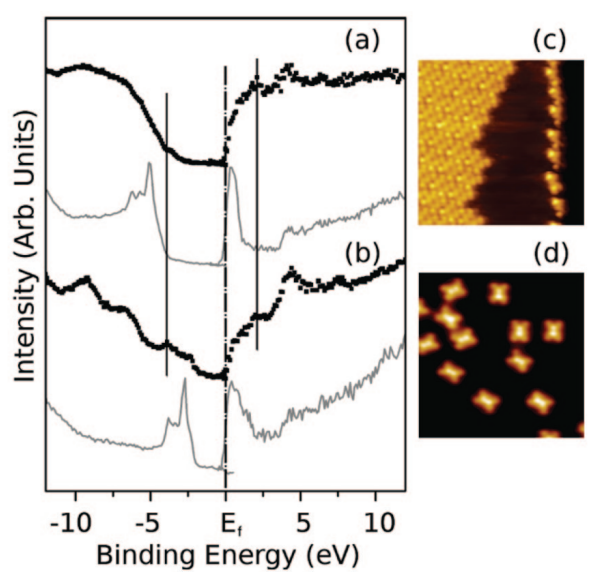

Figure 8. Comparison of photoemission and inverse photoemission spectra of thin film $2 \mathrm{H}-\mathrm{TPP}$ (o.5 ML) on (a) $\mathrm{Ag}$ (111) and (b) $\mathrm{Cu}(111)$, along with the spectra of the corresponding clean substrate at room temperature. STM images of 1/3 ML thick 2H-TPP on (c) $\mathrm{Ag}(111)$ and (d) $\mathrm{Cu}(111)$ are shown on the right side of the Figure $(10 \times 10 \mathrm{~nm}) . U_{\text {bias }}=-0.8 \mathrm{~V}$.

LUMO +1 orbitals possess $b_{1 q}$ symmetry. Given this, the former will be dominated by $\mathrm{d}_{z}^{2}$ levels while the later will be dominated by $\mathrm{p}_{x}$ and $\mathrm{p}_{y}$ levels. This results in a greater cross-sectional overlap of the $2 \mathrm{H}$-TPP HOMO levels with both the $\mathrm{d}_{\mathrm{z}}{ }^{2}$ and $4 \mathrm{~s}$ frontier orbitals of the $\mathrm{Cu}(111)$ system versus only the $5 \mathrm{~s}$ and $6 \mathrm{~s}$ orbitals of the $\mathrm{Au}(111)$ and $\mathrm{Ag}(111)$ systems. Given that the former will have a much larger cross-sectional overlap with the orbitals of the adsorbed porphyrin than will the later, enhanced electron transfer and therefore, tunneling, directly from the tip to the metal substrate via the adsorbed molecules is achieved. This interaction can create enough charge in the molecule-substrate system to hinder $2 \mathrm{D}$ network growth through Coulomb repulsion. This is similar in concept to Co-TPP76,77 and Fe-TPyP56,65 deposited on metal substrates, as the $\mathrm{d}_{\mathrm{z}}{ }^{2}$ orbital of the metal in the molecule provides the same general overlap with the underlying metal that the $\mathrm{Cu}$ has with the adsorbed molecules here.

Given that the substrates are, by themselves, similarly electronegative, it is this greater frontier orbital overlap which transfers a greater amount of charge between the substrate and the adsorbate. The charge transfer is then responsible for the significant electronegativity seen in the HOMO state of the surface $2 \mathrm{H}-\mathrm{TPP}$ on $\mathrm{Cu}(111)$ of Figure $2 \mathrm{~b}$ as well as the apparent modified electronic structure surrounding the molecule.

From the location of the LUMO of the $2 \mathrm{H}-\mathrm{TPP}$ on the macrocycle, as seen in Figure 7, a perturbation of the LUMO by the formation of week $\mathrm{CH}-\pi$ bonds with the phenyl arms of neighboring molecules can be expected. This perturbation may lead to the splitting of the LUMO states by $1.1 \mathrm{eV}$ observed in the inverse photoemission data, see Figure $4 \mathrm{~d}$. This level splitting is observed on $\mathrm{Au}(111)$ and, to lesser extend on $\mathrm{Ag}(111)$ where the $2 \mathrm{H}-$ TPP molecules are observed to form a network structure. ${ }^{57,71,72}$ This splitting is not observable on $\mathrm{Cu}(111)$, where the molecules remain isolated.

In Figure 8 we compare UPS/IPES spectra for submonolayer coverages of $2 \mathrm{H}$-TPP on $\mathrm{Ag}$ and $\mathrm{Cu}$ with STM images taken at such coverages. Striking here is the absence of discernible peaks in the UPS spectra of $2 \mathrm{H}-\mathrm{TPP} / \mathrm{Ag}(111)$. We suggest that the coexistence of different structural phases with fundamentally different orientation relative to the substrate in multiple energetic orientations smear out peaks in the UPS spectra as seen for other adsorbate-surface systems. ${ }^{80}$ DFT calculations support this observation by showing that step-edge sites held significantly higher binding energies than terrace sites for the $2 \mathrm{H}-\mathrm{TPP} / \mathrm{Ag}(111)$ 
system. Electronic features similar to those of free $2 \mathrm{H}$-TPP molecules appear only at coverages above 3 ML where the layer stacking is the dominating structural arrangement.

\section{Conclusion}

It has been demonstrated that the tendency of porphyrins to self-organize is limited by interactions with the substrate. While a rather significant molecule-substrate bond exists for $2 \mathrm{H}$-TPP on all substrates studied, the limiting factor in formation of selforganized islands is apparently the nature of the frontier orbital overlap and resulting electron transfer, which is mainly involving the macrocycles of the molecules.

The self-assembly of near charge neutral $2 \mathrm{H}-\mathrm{TPP}$ molecules into extended 2D networks on $\mathrm{Ag}(111)$ is due to a combination of van der Waals, electrostatic and $\mathrm{CH}-\pi$ interactions between the molecules. The relative orientation of neighboring molecules is mainly given by the $\mathrm{CH}-\pi$ interactions, due to which there is a perturbation of the electronic states of the adsorbed molecules. Charge pickup and dipole formation of $2 \mathrm{H}-\mathrm{TPP}$ on $\mathrm{Cu}(111)$ results in repulsive Coulomb interactions which seem to dominate over attractive intermolecular interactions, thus preventing network formation. A zone of modified electronic structure is observed around the molecules on $\mathrm{Cu}(111)$, which is indicative of such strong molecule-substrate interactions and charge uptake by the molecules. This mechanism seems to be absent for $2 \mathrm{H}$-TPP/ $\mathrm{Ag}(111)$ and $2 \mathrm{H}-\mathrm{TPP} / \mathrm{Au}(111)$, where the orbital overlap differs significantly from that of the $2 \mathrm{H}-\mathrm{TPP} / \mathrm{Cu}(111)$ system. The comparison of our results with published work on Co-TPP, Cu-TPP, and TPyP suggests that the molecule-substrate interaction strength is governed by the molecule's metalation, and not so much by the ligands.

The morphology of the substrate surface is also important as the molecules are observed to preferentially bridge the substrate step-edges before island nucleation starts on the terraces. The discussed examples showed that the properties of $2 \mathrm{D}$ layers of organic materials can be controlled by interactions with the supporting substrate. Specifically, it was shown that the structural arrangement, HOMO-LUMO gap, and details of the electronic structure are determined by the substrate, thereby improving our understanding of planar organic molecular adsorption and self-assembly on surfaces.

Acknowledgment - This work was supported by the National Science Foundation through Grants NSF CAREER (DMR-0747704), NSF Chemistry (CHE-0909580), and NSF MRSEC (DMR-0213808).

\section{References}

1. Kottas, G. S.; Clarke, L. I.; Horinek, D.; Michl, J. Chem. Rev. 2005, 105,1281

2. Vriezema, D. M.; Aragones, M. C.; Elemans, J.; Cornelissen, J.; Rowan, A. E.; Nolte, R. J. M. Chem. Rev. 2005, 105, 1445

3. Anderson, H. L. Chem. Commun. 1999, 2323

4. Wende, H.; Bernien, M.; Luo, J.; Sorg, C.; Ponpandian, N.; Kurde, J.; Miguel, J.; Piantek, M.; Xu, X.; Eckhold, Ph.; Kuch, W.; Baberschke, K.; Panchmatia, P. M.; Sanyal, B.; Oppeneer, P. M.; Eriksson, O. Nat. Mater. 2007, 6, 516

5. Suzuki, T.; Kurahashi, M.; Ju, X.; Yamachi, Y. J. Phys. Chem. B 2002, 106, 11553

6. Fletchner, K.; Kretschmann, A.; Steinrück, H.-P.; Gottfried, J. M. J. Am. Chem. Soc. 2007, 129, 12110
7. Mochida, I.; Suetsugu, K.; Fujitsu, H.; Takeshita, K. J. Phys. Chem. $1983,87,1524$

8. Brulè, E.; Miguel, X. R. d. Org. Biomol. Chem. 2006, 4, 599

9. Zampronio, E. C.; Gotardo, M.; Assis, M. D.; Oliveira, H. P. Catal. Lett. 2005, 104, 53

10. Goldberg, I. Cryst. Eng. Comm. 2008, 10, 637

11. Chou, J.-H.; Kosal, M. E.; Nalwa, H. S.; Rakow, N. A.; Suslick, K. S., In Porphyrin Handbook; Kadish, K.; Smith, K.; Guilard, R., Eds.; Academic Press: New York, 200o; Vol. 6, p 43.

12. Suslick, K. S.; Bhyrappa, P.; Chou, J. H.; Kosal, M. E.; Nakagaki, S.; Smithenry, D. W.; Wilson, S. R. Acc. Chem. Res. 2005, 38, 283

13. Drain, C. M.; Goldberg, I.; Sylvain, I.; Falber, A. Top. Curr. Chem. 2005, 245, 55

14. Goldberg, I. Chem. Commun. 2005, 1243

15. DeVries, L. D.; Choe, W. J. Chem. Crystallogr. 2009, 39, 229

16. Zhou, Y.; Wang, B.; Zhu, M.; Hou, J. G. Chem. Phys. Lett. 2005, 403, 140

17. Drain, C. M.; Nifiatis, F.; Vasenko, A.; Batteas, J. D. Angew. Chem., Int. Ed. 2003, 42, 2670

18. Drain, C. M.; Batteas, J. D.; Flynn, G. w.; Milic, T.; Chi, N.; Yablon, D. G.; Sommers, H. Proc. Natl. Acad. Sci. 2002, 99 ( suppl. 2) 6498

19. Zhang, J.; Sessi, C.; Michaelis, C. H.; Brihuega, I.; Honolka, J.; Kern, K.; Skomski, R.; Chen, X.; Rojas, G.; Enders, A. Phys. Rev. B. 2008, 78, 165430

20. Hai, N. T. M.; Gasparovic, B.; Wandelt, K.; Brökmann, P. Surf. Sci. 2007, 601, 2597

21. Yoshimoto, S.; Yokoo, N.; Fukuda, T.; Kobayashi, N.; Itaya, K. Chem. Commun. 2006, 500

22. Yokoyama, T.; Yokoyama, S.; Kamikado, T.; Mashiko, S. J. Chem. Phys. 2001, 115, 3814

23. Ramoino, L.; vo Arx, M.; Schintke, S.; Baratoff, A.; Güntherodft, H.-J.; Jung, T. A. Chem. Phys. Lett. 2006, 417, 22

24. Spillman, H.; Kiebele, A.; Stöhr, M.; Jung, T. A.; Bonifazi, D.; Cheng, F.; Diederich, F. Adv. Mater. 2006, 18, 275

25. Auwärter, W.; Weber-Bargioni, A.; Reimann, A.; Schiffrin, A.; Gröning, O.; Fasel, R.; Barth, J. V. J. Chem. Phys. 2006, 124, 194708

26. Deng, W.; Fujita, D.; Ohgi, T.; Yokoyama, S.; Kamikado, K.; Mashiko, S. J. Chem. Phys. 2002, 117, 4995

27. Kamikado, T.; Sekiguchi, T.; Yokoyama, S.; Wakayama, Y.; Mashiko, S. Thin Solid Films 2006, 499, 329

28. Bonifazi, D.; Kiebele, A.; Stöhr, M.; Cheng, F.; Jung, T.; Diederich, F.; Spillmann, H. Adv. Func. Mater. 2007, 17, 1051

29. Narioka, S.; Ishii, H.; Ouchi, Y.; Yokoyama, T.; Ohta, T.; Seki, K. J. Phys. Chem. 1995, 99, 1332

3o. Xu, B.; Choi, J.; Caruso, A. N.; Dowben, P. A. Appl. Phys. Lett. 2002, 80, 4342

31. Choi, J.; Borca, C. N.; Dowben, P. A.; Bune, A.; Poulsen, M.; Pebley, S.; Adenwalla, S.; Ducharme, S.; Robertson, L.; Fridkin, V. M.; Palto, S. P.; Petukhova, N.; Yudin, S. G. Phys. Rev. B 2000, 61, 576o

32. Choi, J.; Dowben, P. A.; Ducharme, S.; Fridkin, V. M.; Palto, S. P.; Petukhova, N.; Yudin, S. G. Phys. Lett. A 1998, 249, 505

33. Sokolov, A.; Yang, C.-S.; Yuan, L.; Liou, S.-H.; Cheng, R.; Jeong, H.-K.; Komesu, T.; Xu, B.; Borca, C. N.; Dowben, P. A.; Doudin, B. Europhys. Lett. 2002, 58, 448- 454

34. Xiao, J.; Sokolov, A.; Dowben, P. A. Appl. Phys. Lett. 2007, 90, 242907

35. Xiao, J.; Dowben, P. A. J. Phys. Cond. Matter 2009, 21052001

36. Xiao, J.; Dowben, P. A. J. Mater. Chem. 2009, 19, 2172- 2178 
37. Zhang, J.; McIlroy, D. N.; Dowben, P. A.; Zeng, H.; Vidali, G.; Heskett, D.; Onellion, M. J. Phys. Cond. Matt. 1995, 7, 7185

38. McIlroy, D. N.; Zhang, J.; Dowben, P. A.; Heskett, D. Mater. Sci. Eng., A 1996, 217/218, 64

39. Feng, D.-Q.; Wisbey, D.; Losovyj, Ya. B.; Tai, Y.; Zharnikov, M.; Dowben, P. A. Phys. Rev. B 2006, 74, 165425

40. Hamprecht, F. A.; Cohen, A.; Tozer, D. J.; Handy, N. C. J. Chem. Phys. 1998, 109, 6264

41. Boese, A. D.; Doltsinis, N. L.; Handy, N. C.; Sprik, M. J. Chem. Phys. 2000, 112, 1670

42. Boese, A. D.; Handy, N. C. J. Chem. Phys. 2001, 114, 5497

43. Delley, B. J. Chem. Phys. 1990, 92, 508

44. Delley, B. J. Chem. Phys. 200o, 113, 7756

45. Silvers, S. J.; Tulinsky, A. J. Am. Chem. Soc. 1967, 89, 33311

46. Hamor, M. J.; Hamor, T. A. J. Am. Chem. Soc. 1964, 86, 1938

47. Kano, K.; Fukuda, K.; Wakami, H.; Nishiyabu, R. J. Am. Chem. Soc. 2000, 122, 7494

48. Brede, J.; Linares, M.; Lensen, R.; Rowan, A. E.; Funk, M.; Bröring, M.; Hoffmann, G.; Wiesendanger, R. J. Vac. Sci. Technol. B 2009, 27, 799

49. Eichberger, M.; Marschall, M.; Reichert, J.; Weber-Bargioni, A.; Auwärter, W.; Wang, R. L. C.; Kreuzer, H. J.; Pennec, Y.; Schiffrin, A.; Barth, J. V. Nano Lett. 2008, 8, 4608

5o. http://www.wavefun.com/

51. Sridevi, B.; Jeyaprakash Narayanan, S.; Srinivasan, A.; Reddy, M. V.; Chandrashekar, T. K. J. Porphyrins Phthalocyanines 1998, 2, 69

52. Dobson, J. F.; McLennan, K.; Rubio, A.; Wang, J.; Gould, T.; Le, H. M.; Dinte, B. P. Aust. J. Chem. 2001, 54, 513

53. Pitoŏá, M.; Neogrády, P.; Rezá, J.; Jureka, P.; Urban, M.; Hobza, P. J. Chem. Theo. Comp. 2008, 4, 1829

54. Marchetto, H.; Groh, U.; Schmidt, Th.; Fink, R.; Freund, H.-J.; Umbach, E. Chem. Phys. 2006, 325, 178

55. Klappenberger, F.; Weber-Bargioni, A.; Auwärter, W.; Marschall, M.; Schiffrin, A.; Barth, J. V. J. Chem. Phys. 2008, 129, 214702

56. Auwärter, W.; Weber-Bargioni, A.; Brink, S.; Riemann, A.; Schiffrin, A.; Ruben, M.; Barth, J. V. Chem. Phys. Chem. 2007, 8, 250

57. Brede, J.; Linares, M.; Kuck, S.; Schwöbel, J.; Scarfato, A.; Chang, S.-H.; Hoffmann, G.; Wiesendanger, R.; Lensen, R.; Kouwer, P. H. J.; Hoogboom, J.; Rowan, A. E.; Bröring, M.; Funk, M.; Stafström, S.; Zerbetto, F.; Lazzaroni, R. Nanotechnology 2009, 20, 275602

58. Buchner, F.; Schwald, V.; Comanici, K.; Steinrück, H.-P.; Marbach, H. Chem. Phys. Chem. 2007, 8, 241

59. Buchner, F.; Flechtner, K.; Bai, Y.; Zillner, E.; Kellner, I.; Steinrück, H.-P.; Marbach, H.; Gottfried, J. M. J. Phys. Chem. C 2008, 112,15458

6o. Buchner, F.; Warnick, K.-G.; Wölfle, T.; Görling, A.; Steinrück, H.-P.; Hieringer, W.; Marbach, H. J. Phys. Chem. C 2009, 113, $16450-16457$

61. Auwärter, W.; Weber-Bargioni, A.; Riemann, A.; Schiffrin, A.; Gröning, O.; Fasel, R.; Barth, J. V. J. Chem. Phys. 2006, 124, 194708
62. Auwärter, W.; Klappenberger, F.; Weber-Bargioni, A.; Schiffrin, A.; Strunskus, T.; Wöll, Ch.; Pennec, Y.; Riemann, A.; Barth, J. V. J. Am. Chem. Soc. 2007, 129, 11279-11285

63. Lukasczyk, T.; Flechtner, K.; Merte, L. R.; Jux, N.; Maier, F.; Gottfried, J. M.; Steinrück, H.-P. J. Phys. Chem. C 2007, 111, 3090- 3098

64. Wölfle, T.; Görling, A.; Hieringer, W. Phys. Chem. Chem. Phys. 2008, 10, 5739- 5742

65. Zotti, L. A.; Teobaldi, G.; Hofer, W. A.; Auwärter, W.; Weber-Bargioni, A.; Barth, J. V. Surf. Sci. 2007, 601, 2409-2414

66. Grill, L.; Dyer, M.; Lafferentz, L.; Persson, M.; Peters, M. V.; Hecht, S. Nat. Nanotechnol. 2007, 2, 687

67. Deng, W.; Hipp, K. W. J. Phys. Chem. B 2003, 107, 10736

68. Hipps, K. W.; Scudiero, L.; Barlow, D. E.; Cooke, M. P., Jr. J. Am. Chem. Soc. 2002, 124, 2126

69. Scudiero, L.; Barlow, D. E.; Hipps, K. W. J. Phys. Chem. B 2000, 104, 11899

70. Suto, K.; Yoshimoto, S.; Itaya, K. Langmuir 2006, 22, 10766

71. Zhang, X.-L.; Chen, L.-G.; Lv, P.; Gao, H.-Y.; Wei, S.-J.; Dong, Z.C.; Hou, J. G. Appl. Phys. Lett. 2008, 92, 223118

72. Dong, Z. C.; Zhang, X. L.; Gao, H. Y.; Zhang, C.; Chen, L. G.; Zhang, R.; Tao, X.; Zhang, Y.; Yang, J. L.; Hou, J. G. Nat. Photonics 2009, 4, 50

73. Ringer, A. L.; Sinnokrot, M. O.; Lively, R. P.; Sherrill, C. D. Chem.-Eur. J. 2006, 12, 3821

74. Ding, Y.; Me, Y.; Zhang, J. Z. H.; Tao, F.-M. J. Comput. Chem. 2007, 29, 275

75. Repp, J.; Meyer, G.; Olsson, F. E.; Persson, M. Science 2004, 305, 493

76. Brede, J.; Linares, M.; Kuck, S.; Schwöbel, J.; Scarfato, A.; Chang, S.-H.; Hoffmann, G.; Wiesendanger, R.; Lensen, R.; Kouwer, P. H. J.; Hoogboom, J.; Rowan, A. E.; Bröring, M.; Funk, M.; Stafström, S.; Zerbett, F.; Lazzaroni, R. Nanotechnology 2009, 20, 275602

77. Barlow, D. E.; Scudiero, L.; Hipps, K. W. Langmuir 2004, 20, 4413

78. Olsson, F. E.; Persson, M.; Lorente, N.; Lauhon, L. J.; Ho, W. J. Phys. Chem. B 2002, 106, 8161

79. Fernandez-Torrente, I.; Monturet, S.; Franke, K. J.; Fraxedas, J.; Lorente, N.; Pascual, J. I. Phys. Rev. Lett. 2007, 99, 176103

8o. Peisert, H.; Schwieger, T.; Knupfer, M.; Golden, M. S.; Fink, J. J. Appl. Phys. 2000, 88, 1535

81. Wegner, D.; Yamachika, R; Wang, Y.; Brar, V. W.; Bartlett, B. M.; Long, J. R.; Crommie, M. F. Nano Lett. 2008, 8, 131-135

82. Yoshimura, D.; Ishii, H.; Narioka, S.; Sei, M.; Miyazaki, T.; Ouchi, Y.; Hasegawa, S.; Harima, Y.; Yamashita, K.; Seki, K. Synth. Met. 1997, 86, 2399

83. Khandelwal, S. C.; Roebber, J. L. Chem. Phys. Lett. 1975, 34, 355

84. Zidon, Y.; Shapira, Y.; Shaim, H.; Dittrich, Th. Appl. Surf. Sci. 2008, 254, 3255-3261 